\title{
Semeando a agroecologia e colhendo práticas alimentares saudáveis: um olhar sobre os faxinalenses
}

\section{Sowing agroecology and harvesting healthy feeding practices: a look at the faxindenes}

Adriella Camila Gabriela Fedyna da

Silveira Furtado ${ }^{\prime}$

Islandia Bezerra²

${ }^{\prime}$ Curso de Nutrição. Universidade Federal do Paraná. Curitiba, PR, Brasil.

${ }^{2}$ Departamento de Nutrição. Universidade Federal do Paraná. Curitiba, PR, Brasil.

Correspondência / Correspondence Adriella Camila Gabriela Fedyna da Silveira Furtado

Departamento de Nutrição. Universidade Federal do Paraná.

Av. Prefeito Lothário Meissner, 632, Jardim Botânico, 80210-170, Curitiba, PR, Brasil. E-mail: adriellacamilafurtado@hotmail.com

\section{Resumo}

O sistema agroalimentar dominante vem sendo questionado quanto a sua sustentabilidade ambiental, econômica e social. Nesse processo, a agroecologia tem sido uma estratégia importante para a construção da Soberania e Segurança Alimentar e Nutricional (SSAN), especialmente entre povos e comunidades tradicionais, onde as práticas de produção e consumo de alimentos assumem outro significado. O estudo buscou trazer contribuições para a discussão sobre práticas alimentares dos faxinalenses e sua relação com a sustentabilidade do faxinal. Por meio de uma metodologia qualitativa, foram realizadas 11 entrevistas semiestruturadas, em três diferentes comunidades faxinalenses, localizadas no centro-sul do Paraná. As análises demonstram que os povos faxinalenses, caracterizados como tradicionais, podem ser considerados exemplos concretos de alternativas no que concerne à produção e ao consumo de alimentos, uma vez que se baseiam nos fundamentos da agroecologia e, assim como muitos outros atores, assumem o importante papel de protagonistas na construção de outro sistema alimentar que seja mais sustentável e soberano.

Palavras-chave: Desenvolvimento Sustentável. Segurança Alimentar e Nutricional. Agroecologia. Comunidades Pequenas. 


\section{Abstract}

The dominant food system has been questioned as to its environmental, economic and social sustainability. In this process, agroecology has been an important strategy for the construction of Sovereignty and Food and Nutrition Security (SSAN), especially among peoples and traditional communities, where the practices of production and consumption of food assume different meaning. The study sought to bring contributions to the discussion of feeding practices of faxinalenses and their relationship to sustainable Faxinal. Through a qualitative methodology, 11 semi-structured interviews were conducted in three different faxinalenses communities located in southcentral Paraná state. The analysis showed that these people are characterized as traditional, can be considered concrete examples of alternatives in relation to the production and consumption of food, since they are based on the fundamentals of agroecology and, like many other actors, take on the important leading role in the construction of another food system that is more sustainable and sovereign.

Key words: Sustainable Development. Food Security. Sustainable Agriculture. Small Communities.

\section{Introdução}

A carência de estudos que se dediquem a investigar a gestão do uso comum da terra e da agroecologia como estratégias capazes de materializar a Soberania e Segurança Alimentar e Nutricional (SSAN) tem comprometido o diálogo entre atores e mediadores de políticas públicas no que diz respeito a intervenções mais eficazes. Nesse processo, portanto, ficam marginalizados os aspectos culturais e sociais dos chamados povos e comunidades tradicionais, o que resulta em impactos negativos na manutenção do seu modo de vida pela contínua desvalorização de suas características vitais. ${ }^{1}$

É esse aspecto que o presente artigo se propõe a discutir. O sistema agroalimentar hegemônico atual possui limitações frente às mudanças impostas que vão desde o crescente aumento populacional, que gera maior demanda por alimentos, até a necessidade de questionar, sobretudo, a qualidade dos alimentos produzidos por ele. Sugerem-se, portanto, algumas reflexões sobre certas evidências que indicam as perspectivas insustentáveis desse modelo, que por sua vez, vai de encontro ao que vem sendo publicado quando se trata dos povos e comunidades tradicionais. 
O presente trabalho refere-se a um grupo específico - os faxinalenses - que tem conseguido se diferenciar por seu modo de vida tradicional e singular, conforme apontado por Azevedo \& Rigon. ${ }^{2}$

A definição de Povos e Comunidades Tradicionais constitui o artigo 3. do Decreto n 6.040, de 7 de fevereiro de 2007:

Grupos culturalmente diferenciados e que se reconhecem como tais, que possuem formas próprias de organização social, que ocupam e usam territórios e recursos naturais como condição para sua reprodução cultural, social, religiosa, ancestral e econômica, utilizando conhecimentos, inovacões e práticas gerados e transmitidos pela tradição. ${ }^{3}$

Silva ${ }^{4}$ constrói uma breve análise sobre a evolução da Política Nacional de Desenvolvimento Sustentável dos Povos e Comunidades Tradicionais (PNPCT), na qual ressalta que, em razão de processos históricos diferenciados, segmentos da sociedade brasileira desenvolveram modos de vida próprios e distintos dos demais. Tal realidade conferiu ao país uma diversidade social e cultural que se expressa pela multiplicidade de comportamentos, institucionalidades sociais, línguas, etnias e saberes, ocasionando ao mesmo tempo riqueza sociocultural e invisibilidade perante a sociedade e as políticas públicas de modo geral.

A partir dessas demandas históricas, pode-se dizer que a implementação dessa política vem contribuindo para um processo inclusivo, ainda que lento, no que diz respeito ao reconhecimento dos processos sociais e culturais desses povos. A autora supracitada também afirma que mediante tal política, foi possível estabelecer um elo entre o Estado e esses grupos, dando-lhes visibilidade e ainda permitindo seu acesso a outras políticas universais, de modo a garantir que estas sejam adequadas no atendimento das demandas e das características singulares desse público. ${ }^{4}$

É nesse cenário evolutivo (e nesse caso, destinado a um público específico) que o componente da alimentação será abordado. $\mathrm{O}$ artigo, portanto, analisa e discute as relações sociais e as práticas alimentares de alguns faxinalenses, buscando compreender quais as perspectivas existentes nos processos de produção e consumo dos alimentos desse grupo e, desse modo, entender quais as concepções que os faxinalenses detêm sobre tais práticas alimentares. Além disso, também foi traçado o perfil produtivo de algumas famílias faxinalenses para assim, relacioná-lo com os aspectos referentes à sustentabilidade do Faxinal, considerando, especialmente, as práticas de produção agroecológica.

Assume-se também o posicionamento segundo o qual, ao realizar uma pesquisa dessa natureza, pretende-se trazer uma contribuição ao reconhecimento social, cultural e alimentar desses povos. Soma-se a esse argumento que os povos e comunidades tradicionais, no caso os faxinalenses, fazem parte de uma rede de atores que vem protagonizando de modo singular o processo de construção de outro modelo de desenvolvimento - e aqui se destacam a produção e o consumo sustentáveis e soberanos de alimentos. 


\section{Soberania e Segurança Alimentar e Nutricional: uma breve contextualização}

Por soberania alimentar apreende-se que:

[...] es el derecho de los pueblos a los alimentos nutritivos y culturalmente adecuados, accesibles, producidos de forma sostenible y ecológica. Se trata del derecho de los pueblos a decidir el próprio sistema de alimentación y producción. Esto coloca a quienes producen, distribuyen y consumen alimentos en el centro de los sistemas y de las politicas alimentarias, por encima de las exigencias de los mercados y de las empresas. ${ }^{5,6}$

A sustentabilidade do sistema alimentar brasileiro, assim como de outros países, se encontra seriamente comprometida, e sua garantia só pode ser verificada quando a satisfação das necessidades alimentares em curto prazo está assegurada, sem que haja comprometimento dos recursos naturais renováveis e não renováveis, possibilitando a preservação das condições que garantam disponibilidade de alimentos em longo prazo. Tal panorama não foi alcançado pelo modelo de desenvolvimento agrícola adotado pelo Brasil, evidenciado a partir da década de 1970 com a chamada "Revolução Verde". ${ }^{7}$ Sobre essa assertiva, Siliprandi ${ }^{8}$ contribui com a reflexão de que, para se atingir o desenvolvimento sustentável, uma condição necessária e essencial é a garantia da soberania alimentar de um povo.

Vinculada à Soberania Alimentar está a Segurança Alimentar e Nutricional (SAN), cujo conceito no Brasil, segundo o Conselho Nacional de Segurança Alimentar e Nutricional ${ }^{9,10}$ e incorporado conceitualmente na Lei Orgânica 11.346 - que cria o Sistema Nacional de SAN (SISAN), ${ }^{11}$ é:

[...] a realização do direito de todos ao acesso regular e permanente a uma alimentação saudável, de qualidade, em quantidade suficiente e de modo permanente. Deve ser totalmente baseada em práticas alimentares promotoras da saúde, sem comprometer o acesso a outras necessidades essenciais. Esse é um direito do brasileiro, um direito de se alimentar devidamente, respeitando particularidades e características culturais de cada região.

A partir da concepção contida nessas definições, Bezerra (p. 26) $)^{12}$ sugere um conceito ampliado de Soberania e Segurança Alimentar e Nutricional (SSAN):

[...] direito dos povos definirem suas próprias políticas e estratégias sustentáveis de produção, distribuição e consumo de alimentos que garantam o acesso regular e permanente a uma alimentação saudável, de qualidade, em quantidade suficiente e de modo permanente à luz do direito humano à alimentação adequada e saudável para toda a população. A SSAN deve ser pautada na pequena e média produção, respeitando suas próprias culturas e a diversidade dos modos camponeses, pesqueiros e indígenas de produção agropecuária, além de ser totalmente baseada em práticas promotoras da saúde, sem comprometer o acesso a outras necessidades essenciais. 
A reflexão de Rigon ${ }^{13}$ corrobora essa perspectiva, sobretudo no que diz respeito a construção e implementação de políticas públicas na Política e Sistema de Segurança Alimentar e Nutricional do Estado do Paraná. A autora afirma que tão importante quanto a efetivação da SAN são a existência e o cumprimento da Soberania Alimentar em um país, isto é, se não existir esta última, não há como se garantir a primeira.

Nicholson et al. ${ }^{14}$ chamam a atenção para o processo da construção da soberania alimentar, o que, segundo os autores, requer mudança no atual modelo de produção agrícola dominante que se multiplicou até limites inimagináveis há 50 anos e que trouxe a concentração do poder do sistema agroalimentar, deixando-o nas mãos de algumas multinacionais e transnacionais. Desse modo, reforça-se que as pessoas, as organizações e os movimentos críticos a esse sistema não hesitam em argumentar, exigir e levantar a necessidade de uma mudança no modelo de desenvolvimento que rompa com a lógica de acumulação e exploração própria do capitalismo.

Já Löwen Sahr \& Cunha ${ }^{15}$ enfatizam que, ainda nesse período, o intenso processo de modernização trouxe consigo a concentração de terras, a expulsão de pequenos agricultores e prejuízos ecológicos importantes, que resultaram - pelo menos na Região Sul do Brasil - em grandes áreas de monocultivos (como milho e soja), extensas pastagens de gado e enormes silos de cereais, fazendo surgir uma paisagem monótona e interferindo sobre o sistema social e ecológico tradicional.

Campos \& Campos, ${ }^{16}$ por sua vez, afirmam que, em decorrência da modernização e do desenvolvimento rural durante a implantação das políticas neoliberais e a expansão do capital no campo brasileiro, desenvolveu-se uma forma de produção centrada principalmente na monocultura associada à grande propriedade: o agronegócio. Ainda para esses autores, as monoculturas, sejam quais forem, reduzem a diversidade de fauna e flora, gerando desequilíbrios ambientais. Além de provocarem efeitos negativos no clima, nos recursos hídricos e nos solos, promovem uma sequência de explorações descontroladas sem qualquer compromisso com a sustentabilidade dos recursos naturais, de modo a produzir impactos ambientais irreversíveis.

Na contramão desse processo, os movimentos sociais e ambientais, que defendem a agricultura camponesa, a reforma agrária e a preservação da biodiversidade, emergem, ganham destaque e começam a unir forças, instigados, a princípio, pelos problemas socioambientais decorrentes desse modelo de produção exploratória que é agronegócio. Mais recentemente, vêm incorporando na sua luta o tema da soberania alimentar, conforme destacado por Campos \& Campos. ${ }^{16} \mathrm{E}$ é nesse cenário de lutas e embates políticos, ideológicos, de ação coletiva, disputas pelos meios de produção como terra, água, subsídios que se inserem os povos faxinalenses.

Löwen Sahr \& Cunha ${ }^{15}$ descrevem os faxinalenses - sujeitos que fizeram parte desta pesquisa - como um povo que vem conseguindo permanecer parcialmente afastado dessa modernização 
e tecnificação, resistindo, portanto, ao processo da homogeneização produtiva e preservando seu modo de vida, o que lhe confere uma perspectiva singular em termos culturais.

\section{Povos faxinalenses: da invisibilidade à ação em prol da SSAN}

Os Faxinais correspondem a uma forma de organização social fundamentada num modo de produção camponês tradicional de base familiar, peculiar da região centro-sul do Paraná, que se caracteriza pela utilização da terra de forma coletiva. Fundamentase na integração de três componentes: a) criação de animais, à solta, destacando-se suínos, equinos, bovinos, caprinos, e aves; b) extrativismo da erva-mate, araucária e outras espécies de árvores frutíferas e nativas (guabirobeira, jabuticabeira, pitangueira, cerejeira e araçás), dentro dos chamados criadouros comunitários, terras de uso comum ou ainda terras de criar; c) produção agrícola - áreas destinadas à lavoura - nas terras de planta ou plantar, que ficam localizadas fora do criadouro comum, mas tendem a estar localizadas próximas a ele.

Nos Faxinais, é praticada uma policultura alimentar para autoconsumo, cujo excedente pode vir a ser comercializado, destacando-se o feijão, a batata inglesa, o arroz, o trigo, a cevada, a mandioca e o milho. Os dois últimos alimentos também são utilizados para complementação da dieta dos animais criados à solta - em particular suínos - no período da entressafra das frutas nativas. ${ }^{17-19}$

Por meio do Decreto n 3.446, de 14 de agosto de 1997, o governo do Estado do Paraná passou a reconhecer formalmente a existência de um modo de produção autossustentável denominado "Sistema Faxinal". Legitimando o conceito dos autores supracitados, esse instrumento os enquadra como Áreas de Uso Regulamentado (ARESUR), o que lhes dá direito ao registro no Cadastro Estadual de Unidade de Conservação (CEUC) e, por conseguinte, proporciona a seu município o acesso a recursos do Imposto sobre Circulação de Mercadorias e Serviços (ICMS) Ecológico, para ser utilizado na preservação do Faxinal. ${ }^{20}$

A formação dos Faxinais ocorreu no início do século XVII, como resultado da aliança entre índios escravos (fugitivos das reduções jesuíticas) e negros africanos escravos fugitivos, os quais se fixaram nas matas mistas de Araucárias na região sul e centro-sul do Paraná. Os índios traziam consigo seu modo comunitário de vida e o uso dos recursos naturais em comum, enquanto os negros africanos, a prática da criação de animais soltos, principalmente o porco, e ambos a prática da extração da erva-mate. A junção desses elementos foi de fundamental importância para a construção dos Faxinais. Sua consolidação se deu por meio da contribuição significativa 
de uma parcela de camponeses poloneses e ucranianos imigrantes e parte de camponeses cafuzos que conseguiram escapar do genocídio da Guerra do Contestado, ocorrida no início da segunda década do século XX.19

Ainda de acordo com Tavares, ${ }^{19}$ mediante sua exaustiva pesquisa sobre o assunto, existem diversas formas de terras de uso comum, ainda praticadas em várias partes do mundo. No Brasil, além dos Faxinais, se encontram as Terras de Preto - no Maranhão, Terras de Santo, Terras de Índios, Terras Soltas, Fundos de Pasto e Terras de Herança, as quais têm, em parte, suas origens históricas em Portugal. Também existem formas da prática de terras de uso comum na Espanha (Montes Veciñais e Baldios), em Portugal (Baldios), na França (Vaine Pâtre, Biens Communaux), na Itália (Della Comurione, Le Terre Del Compascuo), em Angola, Colômbia, Alemanha, Inglaterra, Ucrânia, Polônia e outros países. Embora existam características semelhantes entre essas modalidades de uso comum da terra, cada uma possui sua particularidade, e em especial os Faxinais, objeto de estudo deste trabalho, possuem características próprias, como por exemplo, o tipo de bioma e criação, o que os torna diferentes de todos esses modelos.

No que se refere a essas características diferenciadas, segundo Bertussi, ${ }^{21}$ os povos de faxinais - também chamados de faxinalenses - reúnem realidades variáveis e distintas entre si, ou seja, a forma como ocorre a gestão do território pode ser diferente, criando-se um cenário diverso. Por exemplo, os elementos presentes em alguns faxinais não necessariamente estarão presentes em outros e, às vezes, não no mesmo padrão, como seria o caso da existência de animais soltos dentro do criadouro comunitário em determinado faxinal e a criação de animais que ficam cercados dentro do terreno do proprietário em outro, assim como a metragem em relação ao quintal de cada família.

A autora ressalta também que algumas características se encontram presentes em muitos faxinais, como é o caso das moradias estarem localizadas dentro do criadouro. As moradias são frequentemente cercadas em pequenas áreas de terra denominadas de "quintais", onde se cultivam hortaliças, ervas medicinais e culturas de subsistência. O modo como esses indivíduos se relacionam com o território é específico, fundamental e inerente à sua cultura, atuando em permanente situação de resistência e criando suas próprias estratégias de reprodução social. Löwen Sahr \& Cunha ${ }^{15}$ dão ênfase a esta afirmativa quando salientam que o sistema faxinal pode ser visto como uma forma de uso sustentável da mata, uma vez que preserva e protege o ecossistema da Mata com Araucária do Paraná, sem renunciar totalmente ao seu uso e possui técnicas peculiares e até mesmo rudimentares, carregadas de símbolos culturais herdados por gerações.

Bertussi $^{21}$ referencia que, durante o período da modernização da agricultura, muitos territórios de uso comum acabaram por desaparecer, devido aos modos de apropriação dos recursos naturais utilizados pelo modelo de agricultura convencional, que de forma progressiva avançaram pelo 
território faxinalense, provocando a desagregação de muitas comunidades. Contudo, foi a crescente desagregação de seus territórios e os conflitos fundiários que impulsionaram a mobilização desses povos no sentido de promover, em 2005, o $1^{\circ}$ Encontro dos Povos de Faxinais, que teve como resposta o surgimento da Articulação Puxirão dos Povos de Faxinalenses (APF), um movimento social que propõe o papel de representação política dos faxinalenses frente ao governo.

Souza, ${ }^{22}$ por sua vez, aponta que juntamente com esse processo político organizativo, a ação de organizações locais proporcionou a visibilidade social dos faxinalenses enquanto movimento social. Posteriormente, por meio da elaboração do projeto "Cartografia Social e o Dossiê de Conflitos Socioambientais nos Faxinais", denominado Guerra Ecológica no Bioma Floresta com Araucária, sobreveio o início do reconhecimento dos faxinalenses como povos ou comunidades tradicionais, mediante debates estimulados pela criação da Comissão Nacional de Desenvolvimento Sustentável dos Povos e Comunidades Tradicionais (CNPCT). Nessa conjuntura, os povos de faxinais se reconhecem e são identificados como povos e comunidades tradicionais, de acordo com o Decreto Federal $n^{\circ}$. 6.040, de 7 de fevereiro de 2007, que institui a PNPCT.3

Shiraishi Neto et al. ${ }^{23}$ observam que a intensa mobilização política dos povos de Faxinais, assumida desde seu 1 을 Encontro, resultou no reavivamento e na proposição de diversos dispositivos legais, tendo como uma de suas maiores conquistas a Lei Estadual $\mathrm{n}^{\circ}$ 15.673, de 13 de novembro de 2007. De acordo com esse dispositivo, o Estado do Paraná considera os povos faxinalenses patrimônio cultural imaterial do Estado e dispõe sobre seu reconhecimento e territorialidade específica, tendo por base suas características próprias, dentre as quais estão sua cultura e modo de viver particulares, laços de solidariedade comunitária, preservação de suas práticas sociais tradicionais e da biodiversidade, visando à manutenção de sua reprodução física, social, cultural, econômica, ancestral e religiosa. ${ }^{24}$ Segundo Souza, ${ }^{25}$ até esse ano existiam 227 Faxinais mapeados no Estado do Paraná.

Convém ressaltar, portanto, que embora este artigo apresente análises limitadas - considerando especialmente, o universo de comunidades faxinalenses mapeadas - não se pretende aqui generalizar as práticas de produção e consumo de alimentos desses povos, mas evidenciar as singularidades que constituem o sistema faxinal, demonstrando suas especificidades/características, principalmente no que tange à alimentação.

\section{Aspectos metodológicos}

Os procedimentos metodológicos utilizados nesta pesquisa têm um caráter qualitativo que, segundo Minayo et al., ${ }^{26}$ se relaciona com um conjunto de significados, motivos, aspirações, crenças, 
valores, atitudes e hábitos que representam um nível mais real, no que se refere à dinâmica das relações, dos processos e dos fenômenos humanos, que não cabem ser quantificados.

As informações foram coletadas mediante a técnica de estudo de caso, em três comunidades faxinalenses, no meio rural paranaense, a saber: Faxinal dos Telles - município de Pitanga, Faxinal da Saudade Santa Anita - município de Turvo e Faxinal dos Kruger - município de Boa Ventura de São Roque. Entre os tipos de pesquisa qualitativa, o estudo de caso é visto como um dos mais relevantes, pois investiga um fenômeno contemporâneo dentro dos diversos aspectos da vida, sobre determinado indivíduo, família, grupo, comunidade ou fato, e tem por objetivo aprofundar o conhecimento de determinada realidade e enfatizar a complexidade da situação, procurando revelar o grande número de variáveis que a envolvem e a determinam, como afirmam Yin $^{27}$ e Triviños. ${ }^{28}$

No decorrer da coleta de dados, foram realizadas entrevistas semiestruturadas com 11 agricultores faxinalenses, as quais foram registradas em gravador digital. Optou-se por uma amostragem não probabilística por conveniência ou acidental na qual, segundo Gil, ${ }^{29}$ o pesquisador seleciona, conforme seus critérios subjetivos, os membros da população mais acessíveis, bem como os elementos a que tiver mais acesso, admitindo que estes possam representar um universo. Laville \& Dionne ${ }^{30}$ afirmam que o método de seleção desse tipo de amostra prevê que devem ser selecionados elementos até o momento em que se estima ter pesquisado o suficiente, para compreensão das motivações, valores, interpretações e percepções das pessoas, conforme a necessidade de desenvolvimento da pesquisa. As entrevistas foram guiadas por um roteiro de perguntas sobre a compreensão e as experiências que esses sujeitos têm em relação a seu modo de produção, práticas e hábitos alimentares. A organização do roteiro da entrevista semiestruturada, bem como sua realização, seguiram as recomendações de Manzini, ${ }^{31}$ sendo então formuladas perguntas principais para o tema a ser investigado e que visam atingir os objetivos pretendidos, complementadas por outras questões que sejam pertinentes às circunstâncias momentâneas à entrevista. Desta maneira, poderiam surgir informações que não seriam encontradas se as respostas estivessem condicionadas a uma padronização de alternativas. Aqui convém referenciar que os participantes tomaram conhecimento e assinaram o Termo de Consentimento Livre Esclarecido (TCLE), ressaltando que a pesquisa foi realizada no âmbito de um projeto maior devidamente aprovado pelo Comitê de Ética em Pesquisa da Universidade Federal do Paraná (CEP-UFPR), conforme protocolo de número CAAE-0058.0.091.000-08.

Ainda corroborando Manzini, ${ }^{31}$ o roteiro serviu não apenas para coleta de dados básicos, mas como um meio para a pesquisadora se organizar para o momento da entrevista, percebida como um processo de interação social, verbal e não verbal, que ocorre face a face com o entrevistado, o qual supostamente tem as informações que possibilitam analisar o fenômeno em questão, e cuja mediação ocorre essencialmente por meio da linguagem. Durante o trabalho de campo, foram feitos 
registros em diário de campo, registros de gravação de áudio e fotográficos - perante autorização prévia do(a) entrevistado(a) - observação das reais condições de vida, de moradia, de costumes e tradições, produção e consumo de alimentos.

Segundo Cruz Neto, ${ }^{32}$ o trabalho de campo se manifesta não apenas como alternativa de se conseguir uma aproximação com o que se almeja conhecer e estudar, mas também de obter conhecimento a partir da realidade presente no campo. Outro método qualitativo utilizado nesta pesquisa foi a observação participante, cujo objetivo, segundo o mesmo autor, é permitir o aprofundamento sobre a realidade vivida pelos atores sociais em suas próprias conjunturas, tornando possível a percepção de uma variedade de situações e fenômenos dificilmente obtidos a partir de perguntas, já que transmite o que há de mais imprevisível e indeterminado na vida real.

Semelhantemente ao levantamento realizado na pesquisa feita por Silva et al., ${ }^{1}$ foi construído um perfil produtivo qualitativo de cada comunidade, para identificar os produtos da agrobiodiversidade presentes nos faxinais, por meio da listagem dos alimentos produzidos obtida pelo relato dos faxinalenses, além da visita às plantações dos mesmos, visando relacionar os achados com a sustentabilidade do faxinal.

Alguns relatos foram transcritos neste trabalho e, a fim de assegurar o anonimato dos participantes foi utilizada a letra $\mathrm{F}$ (Faxinalense), seguida por indicação numérica, cujo número corresponde à ordem cronológica das entrevistas realizadas durante a pesquisa de campo, em janeiro de 2013. Optou-se por tomar cuidado para não modificar as palavras expressadas pelos participantes, pois estas revelam como o entrevistado concebe e/ou percebe o assunto tratado, e são imprescindíveis para a completa compreensão das respostas.

\section{Agroeocologia e práticas alimentares saudáveis entre faxinalenses}

A pesquisa foi realizada durante o mês de janeiro de 2013 mediante coleta de dados (entrevistas) em três comunidades faxinalenses, localizadas no centro-sul do Paraná. No entanto, convém ressaltar que durante o ano de 2011, por ocasião da execução do Projeto de Pesquisa e Extensão intitulado Plantar, Colher, Comer e Nutrir: o caminho da SAN no meio rural paranaense, foi possível exercer o papel de observadora-participante em diferentes comunidades faxinalenses, considerando sobretudo seu cotidiano em família e com amigos, observando os eventos do dia a dia, principalmente aqueles relacionados às práticas de produção e consumo de alimentos. Fato que justifica a adoção dessa técnica suplementar de análise.

Foram realizadas 11 entrevistas, sendo, respectivamente: um morador do Faxinal dos Telles (município de Pitanga), nove moradores do Faxinal da Saudade Santa Anita (município de Turvo) e um morador do Faxinal dos Kruger (município de Boa Ventura de São Roque). Considerando a questão de gênero, das pessoas entrevistadas, sete eram do sexo masculino e quatro, do feminino. 
Segundo o mapeamento situacional dos Faxinais no Paraná, desenvolvido por Meira, Vandresen \& Souza, ${ }^{33}$ existem 18 Faxinais localizados nos três municípios que compuseram o universo da pesquisa, sendo que 13 estão localizados no município de Turvo, três em Pitanga e dois em Boa Ventura do São Roque, abrangendo um total de 594 famílias.

Para o acesso às comunidades, contou-se com a ajuda de articuladores.

\section{Concepções em torno do modo de produção agroecológica e das práticas alimentares faxinalenses}

As variáveis que predominaram nas falas estavam relacionadas fundamentalmente à alimentação, considerada por eles como: "saudável”, "de boa qualidade”, "necessária para sobrevivência”, "natural”, "pura”, "sadia”, "diferente”, "um tesouro", "uma riqueza”, "tudo” e "suficiente." Predominantemente, esses conceitos se associavam ao fato de que, em sua grande maioria, o consumo dos alimentos pelas famílias provém da própria produção, que por sua vez ganha tais atributos por ser "agroecológica", "diversificada" e "farta”. Há que se considerar também que, ao se referir aos alimentos que produzem, é enfatizado que estes são produzidos sem agrotóxicos, o que significa que são alimentos "sem veneno", "sem conservantes" e "sem transgênicos", atribuindo-se a seu consumo um indicador de qualidade alimentar, que por sua vez se apresenta como importante promotor de saúde.

Boa. Tudo natural. Não tem veneno. É diversificada a produção. (F 1).

Acho muito bom, porque você sabe o que está comendo. Tudo da horta é agroecológico, é produzido sem veneno nenhum, pode-se consumir sem problema. (F 11).

Acho que é uma alimentação sadia, você pode tirar o tomate, passa uma aguinha e come sem medo, não tem veneno, não tem nada, é uma riqueza, não tem dinheiro que paga. (F 8).

Acho muito boa. Tem uma segurança e soberania alimentar muito boa. Eu mesmo fiquei esse período na cidade e a minha alimentação era lá e a gente não consegue ter uma alimentação saudável, e aqui a gente consegue ter uma grande produção natural, orgânica. Eu percebo por mim mesmo, faz uns bons dias que eu tô aqui e vejo a diferença na gente, a alimentação mais saudável. É bem significativo.

[...] a saúde da gente entra pela boca. (F 3).

Os resultados obtidos em pesquisa realizada por Ell, Brandenburg \& Silva ${ }^{34}$ acerca das práticas alimentares entre os agricultores ecológicos - porém não de faxinalenses - assemelham-se aos relatos anteriores, já que trazem evidencias de que, para os agricultores ecologistas, alimentação saudável significa alimentos com ausência de agrotóxicos. Nesses termos, o agrotóxico é definido como "veneno", isto é, havendo a presença dessa substância tóxica no alimento, ele se torna nocivo à saúde. 
No livro Agrotóxicos no Brasil: um guia para ação em defesa da vida, de Flavia Londres, ${ }^{35}$ são explicitados os perigos dos venenos usados na agricultura, destacando estudos sobre o desenvolvimento de sérias doenças neurológicas, hepáticas, respiratórias, renais e cânceres provocados pelos agrotóxicos e enfatizando a questão de que um dos maiores riscos representados por essas substâncias diz respeito aos efeitos prejudiciais que elas provocam na saúde das pessoas.

Essas percepções da segurança que há em saber o que está sendo consumindo e a possibilidade de desfrutar alimentos "sem veneno" conduzem o faxinalense a cultivar seus próprios alimentos, desenvolvendo uma produção para autoconsumo que o leva a contribuir para outro padrão de saúde alimentar e, concomitantemente, com a diversificação da produção. De acordo com Darolt, ${ }^{36}$ a prática da produção agroecológica pode permitir o acesso a uma alimentação mais diversificada por parte das famílias dos pequenos agricultores, nesse caso dos faxinalenses, e a valorização dos recursos locais, tais como contribuir para a melhoria da qualidade de vida e de saúde do agricultor e do consumidor, devido à produção de alimentos livres de substâncias químicas e/ou geneticamente modificadas.

\section{As relações sociais e as formas de aquisição de alimentos entre os faxinalenses}

As formas de aquisição de alimentos para consumo das famílias, segundo relato dos faxinalenses, ocorrem em sua maioria por produção própria (policultura de subsistência), troca com os vizinhos e em sua minoria por meio de compra em mercados. Percebe-se que na produção de alimentos para autocosumo, praticada por todos os entrevistados, existe uma rica diversidade de elementos, como demonstram os seguintes relatos acerca dos tipos de alimentos produzidos:

É só você se planejar, planta um pedacinho, você tem vários tipos de alimentação pra teu gasto, e a saúde é outra. (F 8).

Temo leite crioulo, carne crioula, a horta, mandioca, feijão [...] Aqui pra nós dá as frutas nativas jabuticaba, guavirova, pitanga, araçá, dá também laranja, os cítricos, pinhão [...] Temos uma vaca de leite, porco - 5 leitoa por matriz e 3 reprodutor - 40 a 50 galinha [...]. (F 2).

Agora se for na horta e quiser fazer 4 ou 5 tipos de salada tem, sem fala no feijão, o arroz, o leite, abóbora, mandioca, batata, carne, a banha, o leite caipira, derivados de leite, derivados de fruta, pêssego, doce, maça, caqui, morango, tem uma variedade bem grande, milho verde. (F 3).

Na horta tem todo tipo de verdura: alface, couve, chuchu, tomate, cenoura, repolho e tem arvoredos como, pêra, pêssego, ingá, jabuticaba, limão, laranja, poncã, mexerica, e também tem a criação de porcos, galinhas, vacas de leite e cavalos. O porco, a banha, a carne, tudo é crioulo. Tem de tudo. É muito gostoso morar aqui, porque você tem tudo aqui, tem um monte de coisa que você produz no faxinal, tem as frutas, tem o porco, a galinha, o ovo. Tem bastante variedades. ( $F$ 4). 
Os relatos expostos, sempre com uma entonação de contentamento, corroboram outro estudo realizado por Rigon, ${ }^{37}$ no qual um grupo de agricultores agroecológicos da região centro-sul do Paraná evidencia que a prática da produção para autoconsumo baseada numa variedade de alimentos é considerada estratégia tradicional de fundamental importância para a reprodução social, econômica, biológica e adaptativa dos agricultores. Os relatos abaixo fazem essa constatação.

Eu estou fazendo curso de técnico ambiental [...] e tem um trabalho de pesquisa, onde a gente identificou só numa propriedade em torno de 35 à 40 produtos. Porque se for classificar por espécies como, grãos, por exemplo, o milho, você tem varias espécies, o feijão com 4 a 5 variedades, o arroz, frutas tem em torno de dez variedades, mandioca, batata-doce, batata-salsa, jabuticaba, sem contar o que a natureza oferece para nós, só isso vai dar em torno de 30 espécies. Se for contar as verduras e raízes, da bem mais espécies. Temos repolho, alface, rabanete, beterraba, cenoura, almeirão, couve. (F 5).

A gente tem a erva-mate, tem o pinhão na época, tira do faxinal. [...] a gente tem meio de tudo, o que da aqui, batata doce, mandioca, abobora, hortaliças, beterraba, rabanete repolho, alface, pêssego [...]. Temo porco, galinha, cabrito, peru, ganso, vaca, cavalo, coelho [...]. [...] temo bastante. (F 9).

Aqui nós criamos o porco solto, temo as vaca, cabrito, galinha caipira, cavalo, gado de leite, gado de corte. A horta tem, onde plantamos alface, pra consumo, repolho, mandioca, batata doce, couve, mostarda. (F 10).

Tem um pouco de tudo, já foi colhido um pouco de feijão, tem couve-flor, tem beterraba, repolho, melancia, alface, milho verde. (F 11).

Em sua clássica obra, Brandão ${ }^{38}$ já constatava esse regozijo e orgulho entre as famílias camponesas pesquisadas. Nesta pesquisa não foi diferente; pode-se afirmar que há entre as famílias faxinalenses uma alegria de demonstrar que grande parte do que consomem resulta do seu próprio trabalho sobre a terra. Acrescenta-se a isso, os argumentos de Gazolla \& Schneider, ${ }^{39}$ que afirmam que a produção voltada para o consumo familiar é relevante na autonomia do agricultor, na sociabilidade comunitária e familiar e nas trocas de conhecimentos, contribuindo para o alcance da Segurança Alimentar e Nutricional das famílias.

Nesse mesmo sentido, os resultados de uma pesquisa desenvolvida por Grisa ${ }^{40}$ sobre os papéis que a produção para autoconsumo desempenha para as famílias, a autora enfatiza a contribuição dessa prática para garantir a segurança alimentar, na medida em que cumpre importante função ao manter a satisfação de uma das necessidades principais para a reprodução social: a alimentação. O que, para a autora, significa que se trata de uma estratégia de reprodução relativamente autônoma, visto que diminui a dependência do mercado. Os seguintes relatos podem ajudar a refletir sobre essa assertiva. 
Enchi 50 vidros de pêssego, e ainda vou encher de figo e de pêra, mais uns 30. Esses dias eu tinha vários tipo de coisa pra fazer salada, que eu não consegui trazer tudo pra dentro, meu mercado é ali [...]. [...] tinha de tudo quanto é tipo de salada [...]. (F 8).

O que a gente diz que é do consumo, a gente produz de tudo o que se consome. (F 6).

Aqui na questão da alimentação nós compramos muito pouco. Só o sal, o açúcar, o trigo, pegamos as vezes um litro de vinagre, as vezes usamos limão pra tempera. (F10).

Compra só o básico mesmo, que às vezes não consegue produzir aqui dentro da propriedade. O básico é o açúcar, que nem o trigo (...). (F 6).

Só que a gente pega de fora, mas o que pega de fora é pouco, trigo, açúcar, sal. (F 4).

[...] muitas vezes você não sabe o que ta comprando, nunca você sabe na verdade. Mas a gente até consegue comprar de outros produtores, de outros colegas nossos, de outras regiões, que tem um trabalho junto. [...] o quem não se produz é trocado com outro. (F 5).

Dentre os poucos itens alimentares comumente adquiridos por meio de compra em mercados pelas famílias estão principalmente açúcar, trigo, sal e café. A justificativa utilizada pela maioria para a compra foi o fato de esses alimentos não serem produzidos na comunidade. Apesar de haver a necessidade da aquisição de alguns alimentos básicos, percebe-se que a produção para o autoconsumo possui maior relevância, e assim como ressaltado na pesquisa realizada por Ramos, ${ }^{41}$ é significativa para as famílias na manutenção dos saberes, no acesso a uma alimentação de qualidade e na manutenção de práticas de sociabilidade.

$\mathrm{Grisa}^{40}$ salienta que a produção dos alimentos de base agroecológica - praticada pelos participantes desta pesquisa - mantém homem, natureza e trabalho conectados em forma de coprodução, pois tem como premissa a utilização dos recursos materiais e sociais disponíveis localmente de forma sustentável, em razão de, ao mesmo tempo, permitir sua reprodução, garantindo a existência de ciclos futuros e uma base de recursos autocontrolada.

Em relação à quantidade de alimentos produzidos ser suficiente para o consumo das famílias, todos os entrevistados afirmaram ser suficiente e, além disso, ainda existirem sobras. Geralmente o excesso da produção, quando não é comercializado, se torna importante instrumento para a promoção da sociabilidade. Como verificado por alguns autores e igualmente através do presente trabalho, a frequente troca e/ou doação de alimentos para vizinhos, parentes, amigos, ou a partilha em encontros, não se dá no sentido de suprir necessidades nutricionais, mas no sentido de manter laços de solidariedade, amizade, cooperação e pelo desejo de compartir os alimentos produzidos. ${ }^{34,42,43}$ 


\section{Considerações finais}

O presente trabalho buscou contribuir para a discussão sobre a insustentabilidade do atual modelo hegemônico de produção e consumo de alimentos. Incidiu, portanto, num esforço de representar um grupo que se autoidentifica como povo e comunidade tradicional - os faxinalenses. Estes, como muitos outros atores, assumem o papel de protagonistas importantes na construção de outro sistema alimentar que seja sustentável.

Uma vez que existe crescente demanda por formas alternativas de desenvolvimento mais justas, seguras, saudáveis e ambientalmente equilibradas, apresentou-se aqui a iniciativa dos povos faxinalenses como um dos exemplos de que a prática da agroecologia é uma proposta viável e que vem avançando ao longo dos últimos anos.

Nessa perspectiva, a agroecologia se expressa como uma aspiração e um fomento a outra forma de desenvolvimento, pois, como pode ser observado nos resultados desta pesquisa, infere-se que a prática agroecológica é capaz de servir como instrumento de resistência e de reprodução social, econômica, biológica e adaptativa dos agricultores, ao abrir novos caminhos de afirmação de sua autonomia e domínio das maneiras de produzir e viver. Além disso, é possível afirmar que a prática de utilizar dinâmicas adaptativas e diversificadas no processo produtivo - como defende a agroecologia -, ao privilegiar uma agricultura de baixo impacto ambiental e a não utilização de agrotóxicos (ou de qualquer outro insumo químico), logra-se a redução de danos à biodiversidade, mas sobretudo minimizam-se os riscos à saúde humana. Nos depoimentos dos faxinalenses a respeito de suas concepções em torno de suas práticas alimentares e de produção, torna-se evidente que estas são, em geral, vinculadas a sua concepção de saúde e bem-estar.

O contexto vivenciado pelos agricultores faxinalenses entrevistados mostra que a produção para autoconsumo de base agroecológica praticada tem grande relevância no resgate de saberes e conhecimentos tradicionais e na sociabilidade comunitária, por procurar manter laços de solidariedade, amizade, cooperação e o desejo de compartir os alimentos excedentes ao consumo da família. Além disso, materializa-se como sendo importante estratégia de autonomia, visto que diminui a dependência do mercado, contribuindo para o alcance da Segurança Alimentar e Nutricional das famílias, corroborando os demais resultados aqui referenciados.

Ressalta-se, com este trabalho, assim como explanado por Petersen, ${ }^{44}$ que sem a superação do paradigma da modernização na esfera das instituições públicas, os potenciais endógenos dos territórios - no caso aqui as comunidades faxinalenses - não serão valorizados como forças propulsoras do desenvolvimento rural sustentável. Portanto, diante das exposições, torna-se imperativo defender mudanças profundas nas políticas agrícolas e agrárias, como defendido por Londres, ${ }^{35}$ para que, em paralelo, seja empregando um novo desenho dessas políticas orientadas à promoção da sustentabilidade da agricultura. 
Desse modo, é possível criar condições para que a agricultura ecológica possa de fato se desenvolver e se expandir, e que nesse cenário o protagonismo seja exercido por atores comprometidos não apenas com as questões relativas ao desenvolvimento, mas principalmente com a Soberania e Segurança Alimentar e Nutricional da nação.

\section{Referências}

1. Henning LFC. Agroecologia nos faxinais: saber tradicional e saber científico associados no desenvolvimento de redes de abastecimento alimentar. In: 20o EVINCI; 01-05 out. 2012; Curitiba, Brasil. Curitiba: UFPR; 2012.

2. Azevedo E, Rigon SA. Sistema alimentar com base no conceito de sustentabilidade. In: Taddei JA, Lang RMF, Longo-Silva G, Toloni MHA. Nutrição em saúde pública. Rio de Janeiro: Rubio; 2011. p. 543-60.

3. Brasil. Decreto $n^{\circ}$ 6.040, de 07 de fevereiro de 2007. Institui a Política Nacional de Desenvolvimento Sustentável dos Povos e Comunidades Tradicionais. Diário Oficial da União. 8 fev. 2007.

4. Silva MO. Saindo da invisibilidade: a política nacional de povos e comunidades tradicionais. Revista Inclusão Social 2007; 2(2):7-9.

5. Fórum Mundial sobre Soberanía Alimentaria. Por el derecho de los pueblos a producir, a alimentarse y a ejercer su soberanía alimentaria. Declaración final. Havana, Cuba; 03-07 set. 2001.

6. La Vía Campesina. Las luchas Del campesinado en el mundo. 2009. [acesso em 8 nov. 2011]. Disponible en: http://viacampesina.org/sp/

7. Maluf RS, Menezes F, Valente FL. Contribuição ao tema da segurança alimentar no Brasil. Revista Cadernos Debate. 1996; 4:66-88.

8. Siliprandi E. Desafios para a extensão rural: o social na transição agroecológica. Agroecol. Desenvolv. Rur. Sustent. 2002; 3(3):38-48.

9. Conselho Nacional de Segurança Alimentar e Nutricional. Construção do Sistema e da Política Nacional de Segurança Alimentar e Nutricional: experiência brasileira. Brasília: Consea; 2009.

10. Conselho Nacional de Segurança Alimentar e Nutricional. Por um desenvolvimento sustentável com soberania e segurança alimentar e nutricional. Relatório da III Conferência Nacional de SAN. Fortaleza: Consea; 2007.

11. Brasil. Lei no 11.346, de 15 de setembro de 2006. Cria o Sistema Nacional de Segurança Alimentar e Nutricional (SISAN) com vistas em assegurar o direito humano à alimentação adequada e dá outras providências. Diário Oficial da União, 18 set. 2006.

12. Bezerra I. Nesta terra, em se plantando tudo dá?. Política de soberania e segurança alimentar e nutricional o meio rural paranaense, o caso do PAA. [tese]. Natal: Universidade Federal do Rio Grande do Norte; 2010.

13. Paraná. Política e Sistema de Segurança Alimentar e Nutricional do Estado do Paraná. Curitiba; 2009. 
14. Editorial. La necesidad de un cambio en el modelo agrícola. Revista Soberanía Alimentaria Biodiversidade y Culturas. Out. 2010; (3):2-3.

15. Löwen Sahr CL, Cunha LAG. O significado social e ecológico dos Faxinais: reflexões acerca de uma política agrária sustentável para a região da mata com araucária no Paraná. Revista Emancipação. 2005; 5(1):89-104.

16. Campos C, Campos R. Soberania alimentar como alternativa ao agronegócio no Brasil. Revista Electrónica de Geografía y Ciencias Sociales [Internet]. 2007; 11(245). Disponível em: http://www. ub.edu/geocrit/sn/sn-24568.htm

17. Chang MY. Sistema Faxinal: uma forma de organização camponesa em desagregação no Centro-Sul do Paraná. Londrina: IAPAR; 1988.

18. Gubert Filho FA. O faxinal: estudo preliminar. Curitiba: ITCF; 1987; 2(2):32-40.

19. Tavares LA. Campesinato e os faxinais do Paraná: terras de uso comum. [tese]. São Paulo: Universidade de São Paulo; 2009.

20. Paraná. Decreto no 3.446, de 14 agosto de 1997. Cria as Áreas Especiais de Uso Regulamentado (ARESUR) no Estado do Paraná e da outras providências. Diário Oficial. 14 ago, 1997.

21. Bertussi ML. Faxinais: Um olhar sobre a territorialidade, reciprocidade e identidade étnica. In: Almeida AWB, Souza RM, organizadores. Terras de faxinais. Manaus: Universidade do Estado do Amazonas; 2009. p. 150-166.

22. Souza RM. Da invisibilidade para a existência coletiva: Redefinindo fronteiras étnicas e territoriais mediados pela construção da identidade coletiva de Povos Faxinalenses. In: Anais do II Seminário Nacional Movimentos Sociais, Participação e Democracia. 25-27 abr. 2007; Florianópolis; Brasil. Florianópolis: UFSC; 2007.

23. Shiraishi Neto J. O direito dos povos dos faxinais: as interpretações e as interpretações jurídicas. In: Almeida AWB, Souza RM, organizadores. Terras de faxinais. Manaus: Universidade do Estado do Amazonas; 2009. p. 17-28.

24. Paraná. Lei Estadual no 15.673, de 13 nov. 2007. Dispõe que o Estado do Paraná reconhece os Faxinais e sua territorialidade. Diário Oficial. 13 nov. 2007.

25. Souza RM. Mapeamento social dos faxinais no Pará. In: Almeida AWB, Souza RM, organizadores. Terras de faxinais. Manaus: Universidade do Estado do Amazonas; 2009. p. 29-88.

26. Minayo MCS. Ciência, técnica e arte: o desafio da pesquisa social. In: Minayo MCS, Deslandes SF, Gomes R. Pesquisa Social: teoria, método e criatividade. 23. ed. Petrópolis: Vozes; 2004.

27. Yin RK. Estudo de caso: planejamento e métodos. 3. ed. Porto Alegre: Bookman; 2005.

28. Triviños ANB. Introdução à pesquisa em ciências sociais. São Paulo: Atlas; 2008.

29. Gil A. Métodos e técnicas de pesquisa social. 5. ed. São Paulo: Atlas; 1999.

30. Laville C, Dionne J. A construção do saber. Belo Horizonte: UFMG; 1999. 340 p.

31. Manzini EJ. Considerações sobre a elaboração de roteiro para entrevista semi-estruturada. In: Marquezine MC, Almeida MA, Omote S, organizadores. Colóquios sobre pesquisa em educação especial. Londrina: Eduel; 2003. p. 11-25. 
32. Cruz Netto O. O trabalho de campo como descoberta e criação. In: Minayo MCS, et al. Pesquisa Social: teoria, método e criatividade. 23. ed. Petrópolis: Vozes; 2004.

33. Meira AMK, Vandressen JC, Souza RM. Mapeamento situacional dos faxinais do Paraná. In: Almeida AWB, Souza RM, organizadores. Terras de faxinais. Manaus: Universidade do Estado do Amazonas; 2009. p. 113-131.

34. Ell E, Brandenburg A, Silva DO. Disponibilidade alimentar e concepções alimentares de agricultores ecológicos. In: Brandenburg A, Ferreira ADD. Agricultores ecológicos e o meio ambiente rural: visões interdisciplinares. São Paulo: Annablume; 2012.

35. Londres F. Agrotóxicos no Brasil: um guia para ação em defesa da vida. Rio de Janeiro: AS-PTA; 2011.

36. Darolt MR. Agricultura orgânica: inventando o futuro. Londrina: IAPAR; 2002.

37. Rigon SAA. Alimentação como forma de mediação da relação sociedade natureza: um estudo de caso sobre a agricultura ecológica e o autoconsumo em Turvo. [dissertação]. Curitiba: Universidade Federal do Paraná; 2005.

38. Brandão CR. Plantar, colher, comer: um estudo de caso sobre o campesinato goiano. Rio de Janeiro: Edições Graal; 1981.

39. Gazolla M, Schneider S. A produção da autonomia: os “papéis” do autoconsumo na reprodução social dos agricultores familiares. Revista Estudos Sociedade e Agricultura. 2007; 15(1):89-122.

40. Grisa C. Para além da alimentação: papéis e significados da produção para autoconsumo na agricultura familiar. Revista Extensão Rural. 2007; XIV:5-35.

41. Ramos MO. A “comida da roça” ontem e hoje: um estudo etnográfico dos saberes e práticas alimentares de agricultores de Maquiné. [dissertação]. Porto Alegre: Universidade Federal do Rio Grande do Sul; 2007.

42. Menasche R, organizadora. Agricultura familiar à mesa: saberes e práticas da alimentação no Vale do Taquari. Porto Alegre: UFRGS; 2007.

43. Cambuy AOS. Sistema alimentar dos quilombolas de João Surá: como se mantém e se modificam padrões alimentares. In: Anais da IX Reunião de Antropologia do Mercosul; 10-13 jul. 2011, Curitiba, Brasil. Curitiba: UFPR; 2011.

44. Petersen P. Agroecologia e a superação do paradigma da modernização. In: Niederle PA, Almeida L, Vezzani FM, organizadores. Agroecologia: práticas, mercados e políticas para uma nova agricultura. 2. ed. Curitiba: Kairós; 2013. p. 69-103. 